\title{
Spatial distribution and correlation of dating and premarital sexual experience among male adolescents in Java Islands, Indonesia
}

\author{
Seri Aryati*, Muhammad Rafif, and Zaima Hilmi \\ Department of Environmental Geography, Universitas Gadjah Mada, 55281 Bulaksumur, Yogyakarta
}

\begin{abstract}
The high percentage of male adolescents who had premarital sex and dating in Indonesia on the Java Islands makes it a serious problem. This is exacerbated by the results of research which show that the experience of dating from an early age can increase the likelihood of adolescents engaging in sexual intercourse. This study aims to analyze the correlation between dating experiences and premarital sex as measured by age at first initiation, as well as to determine the spatial distribution of prevalence and correlation. This research is a quantitative statistical study using the Spearman Rank correlation test and also using a map to describe the spatial distribution. The results showed that there are 84 percent of male adolescents in Java who started dating at the age of less than 19 years, also doing sexual intercourse in that age range. This shows male adolescents have experienced a process of greater sexual maturity, so that they have a higher urge to engage in sexual behavior. This condition is in line with the results of the correlation test, where there are 4 provinces in Java which have a positive and significant correlation between the two variables, including Banten, Jakarta, Central Java and West Java. It means the younger the age at first dating adolescents, the younger they will have premarital sex.
\end{abstract}

\section{Introduction}

Adolescence is a transitional period in the human life span that connects childhood and adulthood [1]. Biologically, adolescence is marked by the growth and development of primary and secondary reproductive organs. Meanwhile, psychologically it is characterized by the formation of erratic attitudes and feelings, desires and emotions [2]. This condition encourages adolescents to be in a crisis position in their search for their identity, so they are filled with high curiosity. One of the most highlighted in the process of finding identity is the negative impact it causes, namely the problem of shifting sexual behavior of adolescents. A shift in adolescent sexual behavior can be shown from premarital sexual behavior. As the most populous island in Indonesia, Java Islands has population of adolescents aged 15-24 years more than 24,3 million and this number is 54 percent of total adolescents in Indonesia based on Indonesian Population Census 2020. Data from the 2017 Indonesian Demographic and Health Survey (IDHS) shows a percentage of adolescents who had premarital sex at 7,6 percent, especially for male adolescent who tended to have more premarital sexual intercourse. From that number,
42,4 percent male adolescent who had premarital sexual intercourse lives in Java Islands.

Many studies have shown that sex in adolescents has a very broad impact, one of them is increasing the risk of sexually transmitted diseases. Sex before the age of 17 has a four to fivefold risk of developing disease [3]. Premarital sexual behavior in adolescents is a serious problem. Premarital sexual behavior related to behavior in all forms of behavior from sexual relations with the opposite sex by adolescents before marriage. This behavior can occur by adolescent dating behavior, starting from kissing to touching sensitive areas, which in turn can lead to sexual intercourse [4]. Dating behavior in the current era has become common among adolescents. The 2017 IDHS data shows that 82 percent of adolescents in Indonesia claim to have dated, of which 48 percent are adolescents who live in Java Islands. From this figure, it is known that in dating, 85 percent of adolescents hold hands, 50 percent have embraced, 31 percent have kissed lips and 17 percent have touched or aroused sensitive body parts of his/her couple. As previously mentioned, The study shows that there is a positive and significant correlation between age at first dating and adolescent sexual behavior in Indonesia through the Chi-Square test wirh a p-value of $0.004<0.005[5]$.

\footnotetext{
*Corresponding author: seri.aryati@ugm.ac.id
} 
Another research conducted by Oktriyanto and Alfiasari (2019), they used data from the Survey of Performance Indicators of the National Medium Term Development Plan Program of the National Population and Family Planning 2015. The research aims to analyze dating and sexual behavior among adolescents in Indonesia. The resulth through the Chi-Square test with a $p$ value of 0.000 , show that dating adolescents have a higher likelihood of having premarital sex when compared to non-dating adolescents. This is confirmed through the results where adolescents who are in a relationship holding hands, hugging, kissing lips and touching sensitive areas of the body increase the likelihood of having sex before marriage. The OR value of the correlation of each dating behavior with premarital sex behavior has the lowest value of 4,564 and the highest value of 44,966 for variables touching sensitive areas. This shows that teenagers who touch sensitive areas of his/her couple are more likely to have premarital sex by 44,966 times [6].

This is supported by research data from Bhatta, et al. (2013) conducted in Jhapa district, the eastern part of Nepal on secondary school adolescents. His research shows that 32,6 percent of male adolescents had premarital sex, where more than half, 57,1 percent had sex with his girlfriend [7]. In addition, a study conducted in Pune District, Maharashtra, India by Alexander, et al. (2007) showed that 37 - 49 percent of adolescents who have relationships in dating admitted had sexual intercourse, this number is much higher when compared to adolescents in general, which is only around 15 - 17 percent [8].

The impact due to the positive correlation between dating behavior and premarital sex in adolescents will get worse if the adolescents already know the dating behavior and live it from a younger age. The 2017 IDHS report shows that, on average 45 percent of young women and 44 percent of young men are dating between the ages of 15-17. An even more surprising number is that, there are 74 percent of male adolescents who had sex for the first time between the ages of 15 19 [9]. Therefore, this study will analyze the correlation between dating and premarital sexual behavior as measured by the age at first dating and the age at first sexual intercourse. The gap of this study from previous studies sited in the use of data. This study used secondary data so that it may not be able to explain real-time conditions. Several previous studies in Indonesia, including research conducted by Sari and Rokhanawati (2018), Oktriyanto and Alfiasari (2019) also used secondary data. However, there are differences in the methods used in the research of Oktriyanto and Alfiasari (2019) where in describing the relationship between the two variables dating and premarital sexual experience, they use the Chi Square test, which means that the data is nominal or ordinal data, so in their research only to show relationship between the two variables. Another study conducted by Bhatta, et al. (2013), they also used the Chi Square test to see the relationship between the two variables. In addition, considering that there is no research that examines these two variables in terms of spatial distribution, this study will also examine the spatial distribution of correlation and also its prevalence.

Spatial analysis is currently widely used in various fields to see the distribution of phenomena in an area and even to see the influence of the region on these phenomena. In the research of Tesema, et al. (2020) where spatial distribution aims to identify the distribution and factors of abortion in women of childbearing age in Ethiopia [17]. There is also a study by Sharma, et al. (2021) which uses one of the spatial analysis in describing the spatial disparity of the prevalence of unmet need in India [18]. Therefore, this paper is expected to provide an illustration that there is an interesting relationship between the age of first dating and having premarital sexual intercourse among male adolescents in Java Islands. In addition, through the spatial depiction of the correlation value between the two variables, it can be an interesting study, especially for socio-human research and even in the field of reproductive health.

\section{Method}

This study uses secondary data as an analysis tool. The data used are the results of the 2017 Indonesian Demographic and Health Survey (IDHS). The IDHS is conducted by the Central Statistics Agency (BPS) in collaboration with the National Population and Family Planning Agency (BKKBN) and the Ministry of Health (Kemenkes). The IDHS is also part of the international Demographic and Health Surveys (DHS) Program whose funding is provided by the United States Agency for International Development (USAID).

The IDHS data consists of various components. In order to study the dating behavior of adolescents, the 2017 IDHS component of Adolescent Reproductive Health (KRR) is used. In it, there is a discussion about unmarried women and men aged 15-24 years. The population of the study was 7246 unmarried males aged 15-24 years. The total sample of respondents in this study were 400 adolescent respondents who had a history of dating and had a history of premarital sex. This is in accordance with the variables used in this study were age at first dating and age at first sexual intercourse. The first age variable to have sexual intercourse is male adolescents who admit to having premarital sex according to age. All of these variables were then processed using descriptive statistics and analyzed descriptively quantitatively.

This research uses the Spearman rank correlation test. The spearman rank correlation test is one of the non-parametric statistical tests used to determine the relationship between two variables, namely the independent variable and the dependent variable [10]. This correlation test is used for small amounts of data and uses a minimal ordinal variable scale. In the use of the Spearman correlation test, the data used do not need to be normally distributed.

Based on this, the use of the Spearman correlation test uses the following equation: 
$r_{s}=1-\frac{6 \Sigma d_{i}^{2}}{n\left(n^{2}-1\right)}$

Explanation:

$\mathrm{r}_{\mathrm{s}} \quad=$ Rank Spearman Coefficient Correlatiom

$\mathrm{d}=$ the difference between the pairs of levels

$\mathrm{n} \quad=$ number of pairs [10]

The results of the Spearman rank correlation test were analyzed using 2 hypotheses [11], namely: $\mathrm{H} 0=$ there is no relationship between $\mathrm{X}$ and $\mathrm{Y}$ variables

$\mathrm{H} 1$ = there is a relationship between the $\mathrm{X}$ and $\mathrm{Y}$ variables.

The hypothesis test uses a confidence level of $95 \%$ or an error rate $(\alpha)$ of $5 \%(0.05)$ or $99 \%$ with an error rate of $1 \%(0.01)$ with the following conditions:

1. Sig. $>0.05 / 0.01=\mathrm{H} 0$ is accepted, there is no relationship between $\mathrm{X}$ and $\mathrm{Y}$ variables

2. Sig. $<0.05 / 0.01=\mathrm{H} 1$ is accepted, variable $\mathrm{X}$ has a significant relationship with variable $\mathrm{Y}$ [12]

The correlation coefficient value can be used to measure the strength of the relationship between variables [13]. The correlation coefficient can be interpreted through table 1 as follows:

Table 1. Correlation Coefficient Index

\begin{tabular}{|c|c|}
\hline Coefficient Interval & Correlation Level \\
\hline $0,80-1,00$ & Very Strong \\
\hline $0,60-0,79$ & Strong \\
\hline $0,40-0,59$ & Fairly Strong/Strong Enough \\
\hline $0,20-0,39$ & Weak/Low \\
\hline $0,00-0,19$ & Very Weak/Low \\
\hline
\end{tabular}

Source : [13]

\section{Result and Discussion}

The results and discussion in this research consist of 3 parts, namely the results and analysis of the spatial distribution of the prevalence of adolescents who have dated and adolescents who had premarital sex, crosstabulation analysis between the age at first dating and the age at first having premarital sex, and the last one is a discussion of the correlation result based on Spearman Rank correlation test.

\subsection{Spatial Distribution of Dating and Premarital Sex Among Male Adolescent in Java Islands}

As explained in the method, the variables used are male adolescents who have been dating and have had premarital sex at the age of 15-24 years. Through the figure 1 it is known that the spatial distribution of the percentage of male adolescents who have dated in Java. The results show that the highest percentage of male adolescents who have dated is in West Java Province with a percentage value of 83 percent. Then followed by the provinces of Jakarta, Central Java, Yogyakarta and Banten with a percentage in the range of 70-80 percent. The lowest percentage is occupied by East Java Province with a value of 67.8 percent.

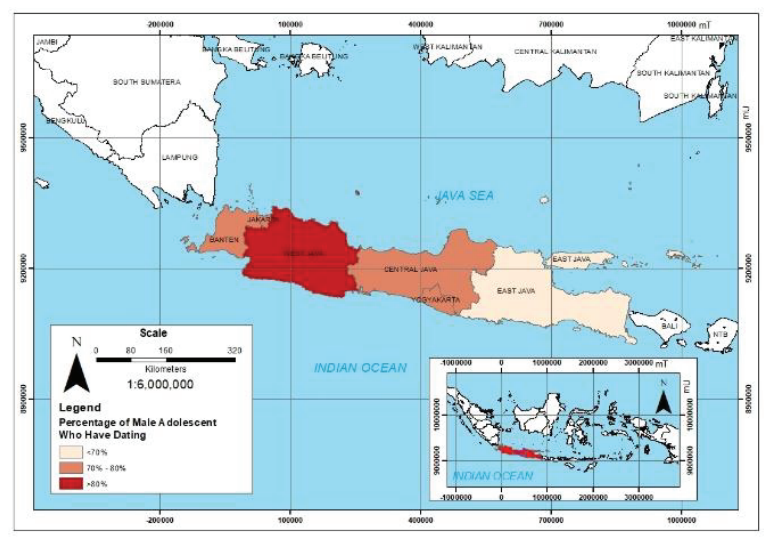

Fig. 1. Spatial Distribution Map of the Percentage of Male Adolescent Who Have Dating

In contrast to the spatial distribution of the percentage of male adolescents who have dated, the spatial distribution of the highest percentage of male adolescents who have had premarital sex is Yogyakarta Province as seen in the figure 2 Yogyakarta Province is the highest with a percentage value of 8.5 percent of the number of successful respondents interviewed. The next position is occupied by the Provinces of Jakarta, West Java, Central Java and East Java with a percentage value of 4-8 percent. Then, the lowest percentage is occupied by Banten Province with a value of 1.9 percent.

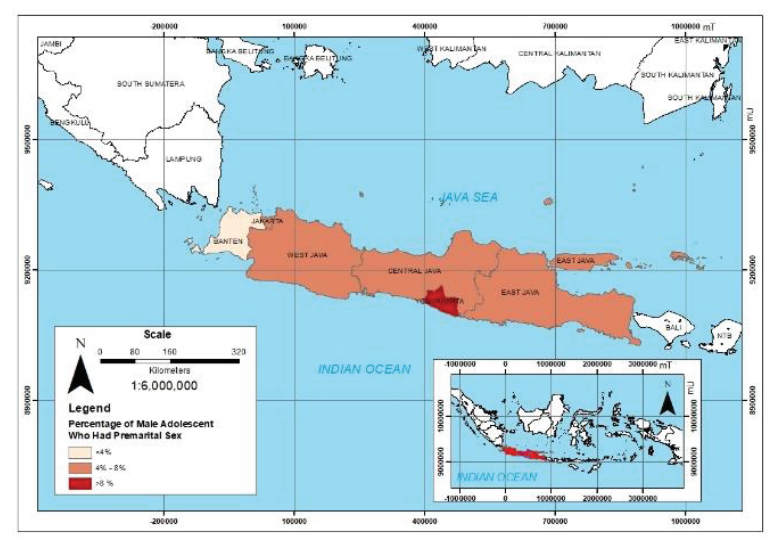

Fig. 2. Spatial Distribution of the Percentage of Male Adolescent Who Had Premarital Sex

\subsection{Cross-Tabulation of Dating and Premarital Sex Among Male Adolescent in Java Islands}

As already mentioned in the Method section, the indicator of dating in this study is measured based on age at first girlfriend and the indicator for premarital sex is age at first sexual intercourse. Thus, the crosstabulation analysis shows the percentage of adolescents according to age who had dating and premarital sex. This percentage is calculated based on the total number of sample respondents. 
Table 2 shows that there are 7,5 percent of adolescents who had a history of dating at first time under the age of 15 , it turns out that they had premarital sex at the age of less than 15 too. There are 32 percent of adolescents who had dating for the first time at the age of less than 15 , they also had premarital sex intercourse at that age range. The largest percentage is 44,5 percent adolescent who had a history of dating for the first time at the age of 15-19 years, were adolescents who had premarital sex with in the same age range.

The table can also show that overall there are 84 percent of adolescents who have had the first premarital sexual intercourse at the age of under 19 and all are adolescents with a history of dating for the first time at the age of under 19 as well. In simple terms, it can indicate that male adolescents in Java with a history of dating for the first time at a relatively young age, will tend to have premarital sex. However, this statement will be described based on the results of the correlation test to determine the strength of the correlation, its direction and significance.

Tabel 2. Cross-tabulation between the percentage of adolescents in dating and premarital sex history based on age

\begin{tabular}{|l|l|l|l|l|l|}
\hline \multicolumn{2}{|c|}{} & \multicolumn{4}{|l|}{ Age at first sexual intercourse } \\
\cline { 3 - 6 } \multicolumn{2}{|c|}{} & $<15$ & $15-19$ & $>19$ & $\begin{array}{l}\text { TOT } \\
\text { AL }\end{array}$ \\
\hline $\begin{array}{l}\text { Age at } \\
\text { first } \\
\text { girlfrien } \\
\text { d }\end{array}$ & $15-19$ & 0 & 44,5 & 12,5 & 57 \\
\cline { 2 - 6 } & $>19$ & 0 & 0 & 0,75 & 0,75 \\
\hline \multirow{2}{*}{\begin{tabular}{l} 
TOTAL \\
\cline { 2 - 6 }
\end{tabular}} & 7,5 & 76,5 & 16 & 100 \\
\hline
\end{tabular}

Source: 2017 IDHS Data Processed

\subsection{Correlation Result Based On Spearman Rank Correlation Test.}

Data testing was carried out based on the results of interviews with 400 unmarried male adolescent respondents with variables in the form of dating behavior as measured from the first age of dating and premarital sex behavior which was measured based on the first age at premarital sexual intercourse. The results of calculations using the Rank Spearman correlation analysis show that there is a significant relationship between the two variables in the Provinces of Banten, Jakarta, West Java and Central Java, while in the Provinces of Yogyakarta and East Java there is no significant correlation between the two variables as seen in table 3.

Table 3. Correlation Coefficient and Significant Value of Spearman's Correlation Test between Age First

Dating and Age First Sexual Intercourse Among Male Adolescent.

\begin{tabular}{|c|l|r|r|}
\hline No. & \multicolumn{1}{|c|}{ Province } & $\begin{array}{c}\text { Correlation } \\
\text { Coefficient }\end{array}$ & $\begin{array}{c}\text { Significant } \\
\text { Value }\end{array}$ \\
\hline 1 & Jakarta & $0,719^{* *}$ & 0,000 \\
\hline 2 & West Java & $0,362^{* *}$ & 0,000 \\
\hline 3 & Central Java & $0,602^{* *}$ & 0,000 \\
\hline 4 & Yogyakarta & 0,072 & 0,777 \\
\hline 5 & East Java & 0,168 & 0,122 \\
\hline 6 & Banten & $0,538^{*}$ & 0,044 \\
\hline
\end{tabular}

* Correlation is significant at the 0.05 level (1-tailed).

** Correlation is significant at the 0.01 level (2-tailed).

Source: Research Result, 2021

Through this table, it is also known that the correlation coefficient value shows the strength of the relationship between the two variables used. The strong relationship is shown in the Province of Jakarta with a correlation coefficient value of 0.719 and the Province of Central Java with a correlation coefficient value of 0.602. A fairly strong relationship is shown in Banten Province with a correlation coefficient value of 0.538 . Meanwhile, Yogyakarta and East Java Provinces did not find a significant correlation between the two variables.

The correlation value in the category is quite strong, indicating that there is indeed a relationship between the age at first dating and the age at first sexual intercourse. This is indicated by the correlation value that is close to the value of 1 , which indicates that the correlation is getting stronger, as happened in Central Java and Jakarta Provinces. Meanwhile, the absence of a significant correlation between the two variables in the Provinces of East Java and Yogyakarta indicates that the age at first dating did not affect the age at first sexual intercourse. In terms of spatial distribution in Java, this correlation is shown in the figure 3 .

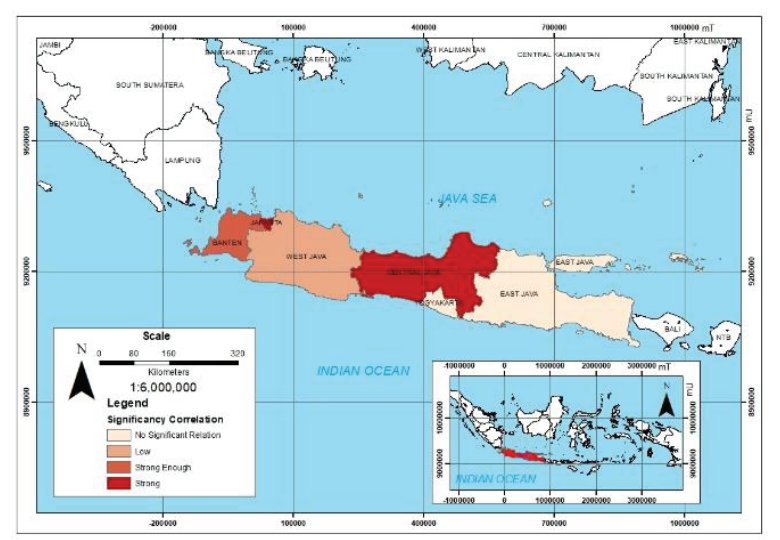

Fig. 3. Spatial Distribution Map of Correlation Age at First Dating and Age at First Sexual Intercourse Among Male Adolescent in Java

The existence of a positive and significant correlation between age at first dating and age at first sexual intercourse has been demonstrated in some previous studies. With a correlation coefficient of 0,023 and a significance of 0,004 , it shows that the younger the age at first dating adolescents, the more 
likely they are to have premarital sex [5]. Other studies have also shown that premarital sex performed at less than 15 years of age is associated with sexual experiences at an early age, one of them is experience in dating [14].

The younger adolescent in dating encourages adolescents to engage in premarital sexual behavior at a relatively young age. This study shows that adolescents tend to have the first sexual intercourse between the ages of 15-19 and the age when they first started dating. Although other studies have shown that there is a relationship between age and sexual behavior, which is adolescents aged 20-24 are 2,3 times more likely to have sexual intercourse than adolescents aged 15-19 years. This is because adolescents aged 20-24 years experience the process of sexual maturity earlier, so they have a greater sexual drive [15]. Therefore, based on the 2017 IDHS, male adolescents in Java Island tend to experience sexual maturity earlier at the age of 15-19 years, considering that teenagers have started dating for the first time and had sex for the first time in that age range.

The risk of sexually transmitted diseases is one of the threats with the increasing prevalence of adolescents engaging in premarital sex in Indonesia, especially Java. Moreover, this risk will increase if in sexual intercourse adolescents do not use contraceptives. Previous studies have found that many adolescents do not practice safe sex [16]. This is also proven from the 2017 IDHS, where 49 percent of male adolescents in Java do not use protection to prevent pregnancy when they first practice sexual intercourse. Furthermore, the results of this study which show that there are four provinces in Java Islands that have a significant correlation, including Banten, West Java, Jakarta, and Central Java, are expected to be a reference for the government, especially in these four provinces, that further studies are needed. It is intended that appropriate programs and policies can be adopted to overcome this phenomenon.

\section{Conclusion}

Based on IDHS 2017, there are 84 percent of male adolescents in Java who started dating at the age of less than 19 years, also doing sexual intercourse in that age range. This shows that at that age, male adolescents have experienced a process of greater sexual maturity, so that they have a higher urge to engage in sexual behavior. This condition is in line with the results of the correlation test between the age of first dating and the age of first having premarital sexual intercourse.

Based on the results of the correlation test between the variables of age at first dating and age at first sexual intercourse in Java Island, it is known that there are 4 provinces that have a significant correlation, namely Banten, West Java, Jakarta, and Central Java, while there are 2 provinces that have no significant correlation that are provinces of East Java and Yogyakarta. The existence of a significant relationship in these 4 provinces indicates that the age at first dating increased the prevalence of the age at first premarital sexual intercourse. This is in line with the correlation coefficient which shows a positive value, which means that the younger the age at first dating adolescents, the younger they will have premarital sex.

This condition is exacerbated by the discovery of the fact that 49 percent of male adolescents in Java who have premarital sex do not use protective equipment for preventing pregnancy when they first have sex. The increased risk of transmission of sexually transmitted diseases (STDs) and early pregnancy can be a serious threat if the right policies or measures are not determined. Therefore, this condition needs the government's attention to be able to review this problem by formulating related policies, one of which is the socialization of early sex education so that adolescents understand better about the dangers of STDs and pregnancy outside of marriage.

\section{Acknowledgment}

I would like to thank Faculty of Geography Universitas Gadjah Mada for the support of conducting this research.

\section{References}

1. J.W. Santrock, Adolescence (2003)

2. K.B. Hidayati, M. Farid, Persona.J.Psi.Indo. 5, 2 (2016)

3. F. Kasim, J.Studi Pemuda 3, 1 (2014)

4. L. Suwarni, D. Ismail, Y.S.Prabandari, MG. Adiyanti, IJPHS 4, 3 (2015)

5. D.E.Sari, D. Rokhanawati, JHTAM 1, 1 (2018)

6. Oktriyanto, Alfiasari, KEMAS 15, 1 (2019)

7. D.N. Bhatta, A.K.Koirala, N. Jha, Health Reinassance 11, 2 (2013)

8. M. Alexander, L. Garda, S. Kanade, S. Jejeebhoy, B. Ganatra, Int. Fam. Plan. Perspect. 33, 4 (2007)

9. National Population and Family Planning Board, Center Bureau of Statistics, Ministry of Health, Indonesia Demographic and Heatlh Survey 2017, (2018)

10. G. E. Dirgantara, M. F. Akbar, R. D. Bekti, JSIK, 3, 2 (2018)

11. D, Apriyanto, R. Harini, JBI, 1, 3 (2012)

12. R. Ilmiyah, E. Darminto, JB, 4, 1 (2020)

13. F. N. Sihombing, JPP, 5, 1 (2017)

14. B.M. Magnusson, J.A. Nield, K.L. Lapane, BMC Public Health 15, 98 (2015)

15. D. Rusmiati, S.P.Hastono, J. National Public Health 10, 1 (2015)

16. L.P.Wong, PLoS One 7, 12 (2012)

17. Tesema, G. A., Mekonnen, T. H., \& Teshale, A. B. PLos One 15, 6 (2020)

18. Sharma H, Singh SK, Srivastava S. SAGE Open (2021) 